\title{
Obstetric results of the multicenter, nationwide, scientific-educational program for pregnant women with gestational diabetes mellitus (GDM)
}

\author{
Monika Żurawska-Kliś ${ }^{1}$, Marcin Kosiński ${ }^{1}$, Ewa Wender-Ożegowska ${ }^{2}$, Łukasz Bartyzel ${ }^{1}$, \\ Elżbieta Matysiak ${ }^{3}$, Bogusława Olak-Białoń ${ }^{4}$, Beata Królikowska-Kobierska ${ }^{5}$, Iwona Towpik 6 , \\ Katarzyna Cypryk ${ }^{1}$ \\ 'Department of Diabetology and Metabolic Diseases, Lodz, Poland \\ ${ }^{2}$ Department of Obstetrics and Women's Diseases, University of Medical Sciences, Poznan, Poland \\ ${ }^{3}$ NZOZ Vitamed, Diabetes Out-Patient Clinic, Kielce, Poland \\ ${ }^{4}$ Diabetes Out-Patient Clinic, City Hospital, Tychy, Poland \\ ${ }^{5}$ Obstetrics Clinic, Perinatology Department, Medical University of Gdansk, Poland \\ ${ }^{6}$ Internal Medicine Clinic, Karol Marcinkowski Regional Hospital, Zielona Gora, Poland
}

\begin{abstract}
Objectives: The aim of the present study was to compare the obstetric results in women with GDM in a Polish population based on the criterion for the diagnosis of GDM.

Material and methods: The study was a questionnaire study covering the data of 2853 patients with GDM treated in centers nationwide in the years 2011-2013. The principles of self-control, glycemic targets and treatment were based on the then-current PDA guidelines. Analysis of the collected data included an assessment of obstetric results based on the diagnostic criteria for GDM. Depending on the result of the glucose tolerance test, the patients were divided into subgroups. Results: $6.28 \%$ of births were preterm, and $47 \%$ were caesarean. A significant difference was observed in the number of preterm births between a subgroups: PDA(+) meeting only criterion $0^{\prime}$ and a PDA(+)meeting only criterion $120^{\prime}(16.67 \%$ vs. $5.83 \%)$; and between $\mathrm{WHO}(+)$ subgroup meeting only criterion $0^{\prime}$ with respect to the subgroup PDA(+) meeting only criterion $0^{\prime}(4.69 \%$ vs. 16.67\%). Significant difference was found in the frequency of LGA between the WHO(-)PDA(+) and WHO(+)PDA(-) subgroups (6,57\% vs. 14.93\%), and between the WHO(-)PDA(+) group and a group of isolated hyperglycemia in $60^{\prime}(6.57 \%$ vs. $12.5 \%)$. Also a significant positive correlation was observed between birth weight, the occurrence of LGA and macrosomia, and maternal weight and BMI before pregnancy.

Conclusions: The results of the analysis indicate the new criteria have greater sensitivity in the prediction of prematurity and birth weight. However, it cannot be ruled out that the final results were affected by the therapeutic intervention employed. Key words: diagnostic criteria, GDM, obstetric outcome, LGA, macrosomia, preterm delivery
\end{abstract}

Ginekologia Polska 2016; 87, 9: 651-658

\section{INTRODUCTION}

Almost all clinical observations suggest that obstetric outcomes in women with gestational diabetes (GDM) are not as good as those in the healthy population $[1,2]$.

Cut-off values of blood glucose for the diagnosis of GDM were previously based on the risk of developing overt type 2 diabetes mellitus (T2 DM) in women after GDM (O'Sullivan's criteria) or used the same cut-off values as for the entire population (WHO 1999) [3]

The first attempt to determine the impact of maternal glycaemia on the developing fetus was a Hyperglycemia and Adverse Pregnancy Outcome (HAPO) study, a prospective, 
multicenter and international analysis of data from a multiethnic group of more than 23,000 pregnant women [4]. The results revealed a linear relationship between the values of glucose identified in the $75 \mathrm{~g}$ oral glucose tolerance test (75 g OGTT) and birth weight, neonatal hypoglycemia, serum C-peptide levels in umbilical cord blood and the frequency of caesarean section births [4]. This relationship was independent of other factors, i.e. age, body mass index (BMI) or a positive family history of diabetes. Based on these results, the criterion for the diagnosis of GDM was proposed as the presence of glucose values associated with a risk factor (OR, odds ratio) of 1.75 for neonatal complications, including infant birth weight above the $90^{\text {th }}$ percentile, C-peptide concentrations greater than the $90^{\text {th }}$ percentile and the fat mass of the newborn above the $90^{\text {th }}$ percentile.

On the basis of this study, the following values for normal glucose in pregnancy during $75 \mathrm{~g}$ OGTT were proposed: fasting $<92 \mathrm{mg} / \mathrm{dL}$, at the $60^{\text {th }}$ minute $<180 \mathrm{mg} / \mathrm{dL}$ and at the $120^{\text {th }}$ minute $<153 \mathrm{mg} / \mathrm{dL}$ [5]. In response, in 2013, the World Health Organization (WHO) approved new criteria for the diagnosis of GDM and recommended their widespread use [6]. The Polish Gynecological and Diabetological Associations (PDA) introduced the new WHO criteria to their clinical guidelines in 2014 [7].

As significant differences in the blood glucose reference values for the diagnosis of GDM exist between the new and the previous PDA criteria, the present study evaluates the results obtained from obstetric diabetes centers participating in the "Dbamy o Mamy" (Caring for Mothers) project, according to the diagnostic criteria for GDM used.

\section{MATERIAL AND METHODS}

\section{Study group}

The study was conducted in the years 2011-2013. A total of 2,853 patients from 56 diabetes outpatient clinics in Poland took part in this study. All patients were diagnosed with GDM in accordance with the PDA recommendations that were applicable at that time. The principles of self-control, glycemic and therapeutic targets were based on these same guidelines.

\section{Testing method}

The study was of an observational and prospective nature. Data was collected using questionnaires specially prepared for the study covering the following domains: maternal age, weight before pregnancy and at delivery, obstetric history, treatment method of GDM and obstetric data on the current pregnancy, incidence of T2 DM amongst $1^{\text {st }}$ degree relatives and anthropometric data.

Obstetric data was obtained either during a follow-up visit to the clinic or by telephone. The data on neonate was based on a discharge summary from hospital and the child's health book.

The following criteria and definitions were used:

- large for gestational age $(\mathrm{LGA})-$ birth weight $>90^{\text {th }}$ percentile for specified sex;

- small for gestational age (SGA) birth weight $<5^{\text {th }}$ percentile for specified sex;

- macrosomy - birth weight $\geq 4,000 \mathrm{~g}$ regardless of the duration of pregnancy.

Assignment to the LGA and SGA categories was based on centile charts for the Polish population [8]. According to the WHO definitions, on-time labor was considered as one which took place between 37 and 42 completed weeks of gestation, and premature labour as one that took place before 37 completed weeks of gestation.

\section{Group selection and statistical analysis}

The study includes a comparative analysis of the criteria for the diagnosis of GDM applicable at that time used by the Polish Diabetes Association (PDA 2010) and the new criteria set by the WHO (WHO 2013).

The criteria of diagnosis of GDM according to PDA guidelines are as follows:

- fasting plasma glucose $>100 \mathrm{mg} / \mathrm{dL}(5.6 \mathrm{mmol} / \mathrm{L})$ and/or plasma glucose $>140 \mathrm{mg} / \mathrm{dL}(7.8 \mathrm{mmol} / \mathrm{L})$ after 2 hours.

The criteria of diagnosis of GDM according to WHO (2013) guidelines are as follows:

- fasting plasma glucose $\geq 92 \mathrm{mg} / \mathrm{dL}(5.1 \mathrm{mmol} / \mathrm{L})$ and/or plasma glucose $>180 \mathrm{mg} / \mathrm{dL}(10 \mathrm{mmol} / \mathrm{L})$ in the first hour of the test and/or plasma glucose $\geq 153 \mathrm{mg} / \mathrm{dL}$ ( $8.5 \mathrm{mmol} / \mathrm{L})$ after 2 hours.

For the purpose of the obstetric data analysis, the total population of pregnant women was divided into several synthetic subgroups according to the diagnostic criteria for GDM that were fulfilled:

- PDA(+) group $(\mathrm{N}=1,446)$ - pregnant women who fulfilled PDA (2010) criteria, regardless of the WHO 2013 criteria;

- WHO(+) group $(\mathrm{N}=1,176)$ - pregnant women who fulfilled WHO (2013) criteria, regardless of the PDA (2010) criteria;

- PDA(+)/WHO(-) group ( $\mathrm{N}=337$ ) - pregnant women meeting only the PDA (2010) criteria;

- PDA(-)/WHO(+) group ( $\mathrm{N}=67)$ - pregnant women meeting only the WHO (2013) criteria;

- PDA(+)/WHO(+) group $(\mathrm{N}=1,109)$ - pregnant women meeting both the PDA (2010) and WHO (2013) criteria;

- PDA(+) or WHO (+) group - a group comprising all patients subjected to statistical analysis $(N=1,513)$ - pregnant women who were diagnosed with GDM based on the PDA (2010) or WHO (2013) criteria. 
The primary analysis of the data involved a comparative analysis of the current version of the PDA (2010) guidelines and the WHO (2013) criteria with regard to time of delivery and birth weight. The anthropometric parameters of the pregnant mothers and the plasma glucose levels identified by the $75 \mathrm{~g}$ OGTT were also correlated with selected obstetric results.

The results were subjected to statistical analysis. The Kolmogorov-Smirnov test was first used to confirm whether the variables had a normal distribution. Normally-distributed dependent and independent variables were compared using the Student's t-test. For variables with a non-normal distribution, independent variables were compared with the Mann-Whitney $U$ test, and dependent variables with the Wilcoxon signed-rank test. Correlations were identified with the Pearson's correlation coefficient for parametric variables, and the Spearman's rank correlation coefficient for non-parametric variables. Statistical calculations were performed using the PQStat statistical package, license no. 01500256 (PQStat Software, Poznan, Polska).

\section{RESULTS}

The study included 2,853 pregnant women from whom completed questionnaires were obtained. For further analysis, 1513 (53.03\%) women with complete data were enrolled. The characteristics of the study group are shown in Table 1.

The diagnosis of GDM by either WHO or PDA criteria at the moment of birth, for term and pre-term deliveries, is presented in Table 2.

In the whole group, $93.78 \%$ of births took place on term. No differences were observed in the duration of pregnancy among study groups. Although the incidence of caesarean births (47\%) did not differ significantly between criteria subgroups, significantly more caesarean sections were recorded in the case of preterm $(73.1 \%)$ than term births (26.9\%) ( $p=0.0023)$.

An analysis of pre-term births showed a statistically significant difference between the PDA(+) subgroup meeting the sole fasting criterion and the $\operatorname{PDA}(+)$ subgroup only meeting the 120-minute criterion $(p<0.05)$. Similarly, a significant difference was also observed between the $\mathrm{WHO}(+)$ subgroup satisfying only the sole fasting criterion and the PDA(+) subgroup satisfying the sole fasting criterion $(p<0.05)$. The results of the analysis are presented in Table 3.

Obstetric outcomes regarding birthweight are shown in Tables 4-6.

There were no statistically significant differences regarding SGA and macrosomia.

Higher percentages of LGA, SGA and macrosomia were observed in the sub-group of $\mathrm{WHO}(+)$ patients with hyperglycemia at the $60^{\text {th }}$ minute compared to patients who had more than one abnormality in the test. However, this difference turned out to be statistically insignificant $(p>0.05)$
Table 1. Anthropometric data of the entire study group

\begin{tabular}{|l|c|}
\hline Parameter & $\mathbf{N}=\mathbf{1 5 1 3}$ patients \\
\hline Age (years) & $30.6 \pm 4.88$ \\
\hline Diagnosis of GDM (week) & $28.9 \pm 3.24$ \\
\hline Body weight before pregnancy $[\mathrm{kg}]$ & $67.2 \pm 14.65$ \\
\hline Body weight when diagnosed with GDM $[\mathrm{kg}]$ & $76.0 \pm 14.61$ \\
\hline Body weight before delivery $[\mathrm{kg}]$ & $77.9 \pm 14.38$ \\
\hline BMI before pregnancy $\left[\mathrm{kg} / \mathrm{m}^{2}\right]$ & $24.8 \pm 5.16$ \\
\hline BMI when diagnosed with GDM $\left[\mathrm{kg} / \mathrm{m}^{2}\right]$ & $28.1 \pm 5.07$ \\
\hline BMI before delivery $\left[\mathrm{kg} / \mathrm{m}^{2}\right]$ & $28.8 \pm 5.07$ \\
\hline Multiparous (\%) & 59.5 \\
\hline History of miscarriage $(\%)$ & 29.5 \\
\hline Insulin treatment $(\%)$ & 29.3 \\
\hline
\end{tabular}

Table 2. The incidence of preterm and term deliveries in individual groups depending on the applied criterion for the diagnosis of GDM

\begin{tabular}{|l|c|c|c|c|}
\hline & $\begin{array}{c}\text { Total } \\
\mathbf{N}\end{array}$ & $\begin{array}{c}\text { Pre-term } \\
\text { delivery } \\
\mathbf{N}(\%)\end{array}$ & $\begin{array}{c}\text { Term } \\
\text { delivery } \\
\mathbf{N}(\%)\end{array}$ & ANOVA \\
\hline $\begin{array}{l}\text { PDA(+) } \\
\text { or WHO(+) }\end{array}$ & 1513 & $95(6.28)$ & $1418(93.72)$ & \\
\hline PDA(+) & 1446 & $92(6.36)$ & $1354(93.64)$ & \\
\hline WHO(+) & 1176 & $75(6.38)$ & $1101(93.62)$ & $\begin{array}{l}X^{2}=0.539 \\
\mathrm{p}=0.996\end{array}$ \\
\hline $\begin{array}{l}\text { PDA(+) } \\
\text { and WHO(+) }\end{array}$ & 1109 & $72(6.49)$ & $1037(93.51)$ & \\
\hline PDA(+)WHO(-) & 337 & $20(5.93)$ & $317(94.07)$ & \\
\hline PDA(-)WHO(+) & 67 & $3(4.48)$ & $64(95.52)$ & \\
\hline
\end{tabular}

PDA(+) patients with fasting hyperglycaemia had nearly twice the rate of LGA and a higher incidence of macrosomia than the group with hyperglycaemia after 120 minutes. These differences were also apparent when compared with patients demonstrating glucose levels above normal levels at both time points. Further analysis revealed a weak correlation between fasting plasma glucose (FPG) and birth weight (Fig. 1). No correlation was observed between the glucose concentration after 60 or 120 minutes in $75 \mathrm{~g}$ OGTT and birth weight. Similarly, no significant correlation was found between glucose values at any time during the $75 \mathrm{~g}$ OGTT test and either LGA, SGA or macrosomia ( $p>0.05$ ).

In addition, no significant correlation was observed between the number of fulfilled diagnostic criteria by which GDM was diagnosed and the obstetric results. Similarly, no correlation was found between the risk of preterm delivery and the presence of glycaemia at any time point nor the number of fulfilled criteria. However, a statistically significant, but weak, correlation was seen between neonatal birth weight and maternal weight before pregnancy $(r=0.162$; $p<0.0001)$ (Fig. 2), BMI before pregnancy $(r=0.112$; 
Table 3. The incidence of pre-term and term deliveries, depending on when 750GTT was applied and the number of fulfilled criteria for the diagnosis of GDM

\begin{tabular}{|c|c|c|c|}
\hline \multirow{3}{*}{ Diagnosis of GDM } & Pre-term delivery & Term delivery & \multirow{3}{*}{ ANOVA } \\
\hline & \multicolumn{2}{|c|}{ WHO(+) patients } & \\
\hline & N (\%) & $\mathbf{N}(\%)$ & \\
\hline Only $0^{\prime}$ criterion $(\mathrm{N}=128)$ & $6(4.69)^{*}$ & $122(95.31)$ & \multirow{3}{*}{$\begin{array}{l}x^{2}=1.26 \\
p=0.51\end{array}$} \\
\hline Only $60^{\prime}$ criterion $(\mathrm{N}=111)$ & $8(7.21)$ & $103(92.79)$ & \\
\hline Only $120^{\prime}$ criterion $(\mathrm{N}=458)$ & $21(4.59)$ & $437(95.41)$ & \\
\hline 1 criterion $(N=697)$ & $35(5.02)$ & $662(94.98)$ & \multirow{3}{*}{$\begin{array}{l}x^{2}=9.607 \\
p=0.082\end{array}$} \\
\hline 2 criteria $(N=396)$ & $39(9.85)$ & $357(90.15)$ & \\
\hline \multirow[t]{3}{*}{3 criteria $(N=80)$} & $7(8.75)$ & $73(91.25)$ & \\
\hline & \multicolumn{2}{|c|}{ PDA(+) patients } & \multirow{2}{*}{$\mathbf{p}$} \\
\hline & $\mathbf{N}(\%)$ & $\mathbf{N}(\%)$ & \\
\hline Only $0^{\prime}$ criterion $(\mathrm{N}=36)$ & $6(16.67)^{*}$ & $30(83.33)$ & \multirow{2}{*}{$p=0.019$} \\
\hline Only $120^{\prime}$ criterion $(\mathrm{N}=1234)$ & $72(5.83)$ & $1162(94.17)$ & \\
\hline 1 criterion $(N=1270)$ & $78(9.09)$ & $1192(90.01)$ & \multirow{2}{*}{$p=0.52$} \\
\hline 2 criteria $(N=173)$ & $13(6.05)$ & $160(93.95)$ & \\
\hline
\end{tabular}

*Statistically significant

Table 4. The frequency of SGA, LGA and macrosomia based on PDA and WHO diagnostic criteria for GDM in pregnant women

\begin{tabular}{|c|c|c|c|c|c|}
\hline Criterion of diagnosis & $\begin{array}{c}\text { Total } \\
\mathbf{N}\end{array}$ & $\begin{array}{c}\text { SGA } \\
\mathrm{N}(\%)\end{array}$ & $\begin{array}{l}\text { LGA } \\
\text { N (\%) }\end{array}$ & $\begin{array}{l}\text { Macrosomia } \\
\text { N (\%) }\end{array}$ & ANOVA \\
\hline $\mathrm{PDA}(+)$ or $\mathrm{WHO}(+)$ & 1513 & $149(9.87)$ & $135(8.94)$ & $135(8.94)$ & \multirow{7}{*}{$\begin{aligned} x^{2} & =5.85 \\
p & =0.93\end{aligned}$} \\
\hline PDA(+) & 1446 & $141(9.77)$ & $125(8.66)$ & 124 (8.59) & \\
\hline WHO(+) & 1176 & $114(9.70)$ & $113(9.62)$ & $105(8.94)$ & \\
\hline $\mathrm{PDA}(+)$ and $\mathrm{WHO}(+)$ & 1109 & $106(9.57)$ & $103(9.30)$ & $83(8.48)$ & \\
\hline WHO(-)PDA(+) & 337 & $35(10.45)$ & $22(6.57)^{*}$ & $30(8.96)$ & \\
\hline WHO(+)PDA(-) & 67 & $8(11.94)$ & $10(14.93)^{*}$ & $11(16.42)$ & \\
\hline Isolated WHO(+) 60' PDA(-) & 48 & $6(12.5)$ & $6(12.5)^{*}$ & $8(16.67)$ & \\
\hline
\end{tabular}

*Statistically significant

Table 5. The child's birth weight for the WHO (+) GDM patients diagnosed by OGTT according to time and number of fulfilled criteria

\begin{tabular}{|l|c|c|c|c|c|}
\hline Time criterion & $\begin{array}{c}\text { Total } \\
\text { N }\end{array}$ & $\begin{array}{c}\text { LGA } \\
\text { N (\%) }\end{array}$ & $\begin{array}{c}\text { SGA } \\
\text { N (\%) }\end{array}$ & $\begin{array}{c}\text { Macrosomia } \\
\text { N (\%) }\end{array}$ & ANOVA \\
\hline Only 0' criterion & 128 & $10(7.81)$ & $12(9.38)$ & $8(6.25)$ \\
\hline Only 60' criterion & 111 & $13(11.71)$ & $15(13.51)$ & $13(11.71)$ \\
\hline Only 120' criterion & 458 & $42(9.17)$ & $43(9.39)$ & $39(8.52)$ & $X^{2}=3.06$ \\
\hline 1 criterion & 697 & $65(9.33)$ & $70(10.04)$ & $60(8.61)$ & 0.54 \\
\hline 2 criteria & 396 & $48(12.12)$ & $44(11.11)$ & $45(11.36)$ & \\
\hline 3 criteria & 80 & $13(16.25)$ & $6(7.50)$ & $8(10.00)$
\end{tabular}

\begin{tabular}{|l|c|c|c|c|c|}
\hline \multicolumn{2}{|c|}{ Table 6. The child's birth weight, for the PDA (+) GDM patients diagnosed by OGTT according to time and number of fulfilled criteria } \\
\hline Time criterion & Total & LGA & SGA & Macrosomia & N (\%) \\
\hline Only $0^{\prime}$ criterion & N (\%) & N (\%) & $4(11.11)$ & $X^{2}=2.95$ \\
\hline Only $120^{\prime}$ criterion & 36 & $6(16.67)$ & $2(5.56)$ & $108(8.75)$ & $p=0.22$ \\
\hline 1 criterion & 1234 & $100(8.10)$ & $127(10.29)$ & $112(8.82)$ & $X^{2}=3.72$ \\
\hline 2 criteria & 1270 & $106(8.35)$ & $129(10.16)$ & $11(6.36)$ & $p=0.155$ \\
\hline
\end{tabular}




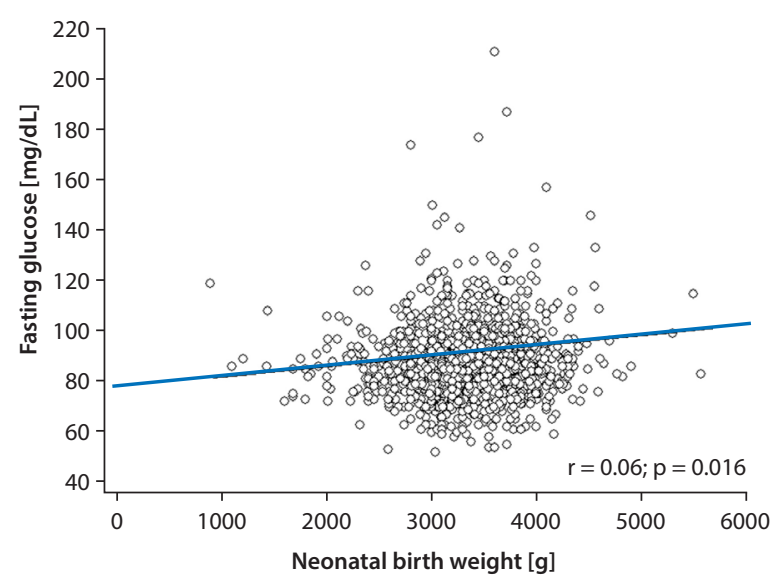

Figure 1. The correlation between maternal fasting plasma glucose and neonatal birth weight within the whole studied group

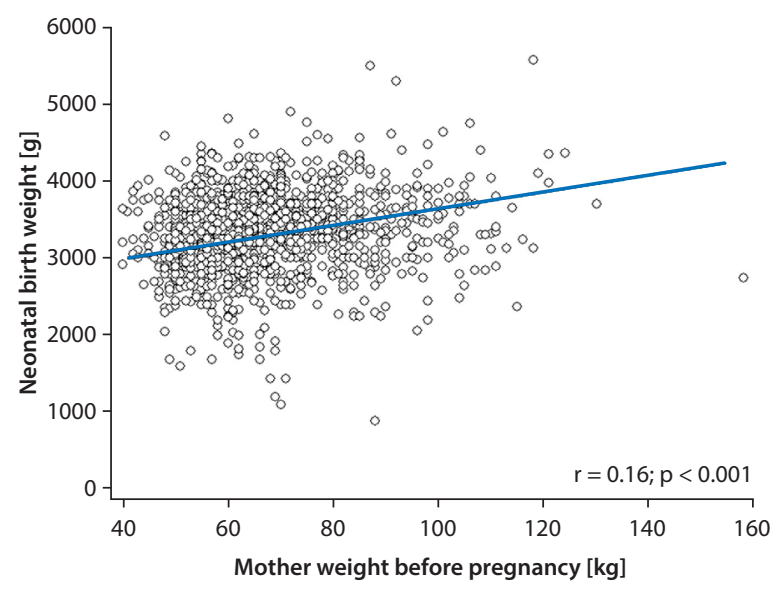

Figure 2. The correlation of maternal body weight (before pregnancy) with neonatal body weight in the whole studied group

$\mathrm{p}<0.0001)$ and the relative weight gain during pregnancy defined as the quotient of the weight gain by weight before pregnancy in kilograms $(r=0.118 ; p<0.001)$. A positive correlation was observed between the occurrence of LGA and maternal weight before pregnancy $(r=0.156 ; p<0.0001)$, BMI before pregnancy $(r=0.13 ; p<0.0001)$ and BMI before delivery $(r=011 ; p<0.0001)$. The mother's body weight before pregnancy also correlated positively with macrosomia $(r=0.121 ; p<0.0001)$.

\section{DISCUSSION}

Before 2013, WHO guidelines recommended the same cut-off values for the diagnosis of diabetes in pregnant women as in the entire population. However, this choice of criterion seemed to be inappropriate as hormonal changes during pregnancy alter carbohydrate metabolism: physiologically lower fasting and higher postprandial plasma glucose values are found during pregnancy. It remained unclear whether and to what extent these slight differences in glu- cose concentration may affect the fetus, especially since glucose is only one of many factors influencing the development of the fetus. The Atlantic Study points to factors such as obesity, genetic factors, smoking and the presence of co-morbidities, and therefore, any assessment of direct glucose participation was problematic, as was establishing acceptable glucose levels during pregnancy. However, prospective analysis of prenatal blood glucose values in the HAPO study demonstrated the continuous nature of the impact of maternal glycaemia on parameters such as birth weight, the C-peptide concentration in cord blood or neonatal risk of hypoglycaemia. The results of this study became the basis for the development of new guidelines, which lowered the cut-off value for diagnosis of GDM for fasting glucose levels while simultaneously increasing value for blood glucose 2 hours after an oral glucose load, compared to WHO criteria. It was also found that exceeding only one of the three plasma glucose levels in an OGTT during pregnancy carries the same risks for the newborn as increasing two or three values.

The present study is a prospective analysis of the obstetric outcome of women with GDM diagnosed according to the PDA criteria, by evaluating the degree to which the application of the new WHO (2013) criteria would affect the obstetric results observed in the population. In this study, $94 \%$ of all patients delivered on term, and no difference was observed between the incidence of prematurity between the assessed groups, regardless of the criterion used, and the fulfilled GDM diagnostic criteria. Analysis of the moment of birth, depending on the time point when the blood glucose was elevated showed a statistically significant difference only between a subset of the $\mathrm{WHO}(+)$ only met the fasting criterion (more than $92 \mathrm{mg} / \mathrm{dL}$ [5.1 $\mathrm{mmol} / \mathrm{L}]$ ), and a similar subgroup of PDA(+) fulfilled the fasting criterion (above $100 \mathrm{mg} / \mathrm{dL}[5.6 \mathrm{mmol} / \mathrm{L}])$. This demonstrates the critical role of fasting glucose on the course of fatal development. However correlation analysis showed no relationship between the risk of preterm delivery and the presence of glycaemia at any time point nor the number of fulfilled criteria. The results of our analysis are similar to those in the HAPO study, in which the rate of preterm births was $6.9 \%$ and the OR for preterm delivery was comparable to glucose levels at all three time points.

Our findings concerning the fulfilled diagnostic criteria indicated higher frequencies of LGA, SGA and macrosomia in the $\mathrm{WHO}(+) \mathrm{PDA}(-)$ group but the only statistically significant differences were found with regard to LGA between $\mathrm{WHO}(+)$ PDA(-) and WHO(-)PDA(+) groups as well as between the WHO(-)PDA(+) group and a group with isolated hyperglycaemia in the first hour of the test (both $p<0.05$ ).

Hence, pregnant mothers who met the diagnostic criteria for GDM based on elevated fasting glucose levels 
above $100 \mathrm{mg} / \mathrm{dL}$, more often gave birth to children with macrosomia, which confirms that FPG has a considerable impact on the induction of excessive fetal growth. This is further confirmed by the fact that in the group in which GDM diagnosis was based on blood glucose above $92 \mathrm{mg} / \mathrm{dL}$, the incidence of LGA was almost half this value. Therefore, the updated WHO guidelines are justified in introducing changes such as a reduction in FPG value, with a simultaneous increase in post-load glucose criterion and adding a criterion after 1 hour.

In the total group, 48 patients with isolated hyperglycaemia above $180 \mathrm{mg} / \mathrm{dL}(10 \mathrm{mmol} / \mathrm{L})$ were identified in the first hour of the test. The percentage of LGA, SGA and macrosomia were also higher in this group, although not so significantly, than in fasting patients or those in the $2^{\text {nd }}$ hour of hyperglycaemia, regardless of the adopted PDA or WHO criterion. It remains uncertain whether any of the glucose values identified by $75 \mathrm{~g}$ OGTT are more applicable for estimating the risk of complications and determination of medical goals. LGA most common occurred in the group of patients meeting the fasting plasma glucose PDA criterion (16.67\%), and the least so in those fulfilling the fasting WHO criterion (7.81\%) for all time points when abnormal glycaemia was found $(0,60$, and 120 minutes).

This difference is not surprising because deeper metabolic disorders might be expected at the higher cut-off values for FPG in the PDA criterion ( $100 \mathrm{mg} / \mathrm{dL}$ ), with consequently worse obstetric results. Correlation analysis showed no dependence between glucose values, including FPG, and the incidence of LGA, macrosomia or prematurity.

In the $\mathrm{WHO}(+)$ patients, the greatest percentage of the LGA, and macrosomia was observed in the subgroup with hyperglycaemia identified in the $60^{\text {th }}$ minute of $75 \mathrm{~g}$ OGTT - both in comparison to the other time points (isolated or not), and compared to patients who met 2 or 3 criteria. In the PDA(+) patients, the highest percentage of LGA and macrosomia was observed in patients with identified fasting hyperglycaemia. However, these differences were not statistically significant. In the HAPO study, glucose in the first hour of $75 \mathrm{~g}$ OGTT, after taking into consideration other factors, was found to be the only predictor of clinical neonatal hypoglycaemia, while fasting blood glucose proved to be the strongest predictor of elevated levels of C-peptide in umbilical blood [4].

A review of Polish studies by Zawiejska et al. indicates the presence of fasting hyperglycaemia as a predictor of increased risk of obstetric complications. Fasting hyperglycaemia, based on WHO criteria, was associated with poor metabolic control, a more frequent need to initiate insulin therapy, and increased incidence of macrosomia, while hyperglycaemia after 2 hours was associated only with a higher frequency of pregnancy-induced hypertension [9].
The correlation analysis in the present study revealed no significant correlation between the number of fulfilled diagnostic criteria in subsequent time points and the obstetric results. A study by Ferrara, also conducted in a multi-ethnic group, found an increased risk of macrosomia, hypoglycaemia, and neonatal hyperbilirubinaemia to be associated with an increased chance of abnormal blood glucose values according to the American Diabetes Association guidelines of the time [10].

The results of the correlation analysis in this study found no relationship between neonatal birth weight and the concentration of glucose at any time point. However, the HAPO study reports a strong linear positive correlation between glucose concentration and neonatal birth weight and the concentration of $\mathrm{C}$-peptide in the umbilical cord blood. The authors clearly determined cut-off values at which the risk should be considered elevated. A slightly weaker relationship was observed in relation to the incidence of preeclampsia, preterm delivery, caesarean sections, perinatal injuries, clinical neonatal hypoglycaemia, jaundice and the need for neonatal intensive supervision [4]. Hence, the prior criteria do not reflect the real risk of perinatal complications and did not have sufficient sensitivity for identifying pregnant women with an increased risk of perinatal complications.

A recently published Danish study conducted in women with mild glucose intolerance also found a linear relationship between plasma glucose level and 2-h $75 \mathrm{~g}$ OGTT score and pregnancy complications including frequency of caesarean sections, premature births, incidence of shoulder dystocia and macrosomia [2]. Another analysis of the same group found a linear relationship between fasting glucose and the incidence of macrosomia [1]. Similarly, a study conducted in the United States in an ethnically diverse group found a linear relationship between blood glucose levels, both fasting and after two hours, and macrosomia [11].

The undesirable effects of hyperglycaemia in the fetal period not only result in an increased risk of obstetric complications. Long-term observations suggest that children with LGA are characterized by a higher incidence of glucose intolerance, diabetes and obesity later in life, and girls of mothers with GDM have an increased risk of GDM in the future [12-14]. Ogonowski et al. report that low birthweight in girls constituted a risk factor for gestational diabetes, and high birth weight increased the risk of obesity in the periconceptional period [15].

The new, stricter WHO criteria were met with skepticism, particularly concerning the costs and benefits of the adopted therapeutic strategies to women with mild hyperglycaemia. Other studies, however, seem to justify tightening the criteria. The results of the Australian Carbohydrate Intolerance Study in Pregnant Women (ACHOIS) study indicate that treatment of gestational diabetes re- 
duces perinatal morbidity and improves the quality of life in relation to health status [16]. The intervention group demonstrated significantly lower rates of serious perinatal complications. In addition, the children had significantly lower mean birth weight, a significantly smaller percentage had LGA or macrosomia, and no difference was found in the incidence of births with SGA. This group also demonstrated lower weight gain during pregnancy and a reduced incidence of pre-eclampsia. However, the intervention group also demonstrated a higher incidence of indications for inductions of labor, the children were born slightly earlier, and a higher percentage of children were admitted to the neonatal unit, with a similar incidence of caesarean sections. The authors suggest that the more frequent need for induction of labor and increased supervision of the newborn could be due to greater awareness of patient illness by the physician and a greater propensity to intervene. The authors conclude that the more frequent induction of labor and greater number of earlier births at least partly account for the reduced mean birth weight and lower incidence of preeclampsia in the intervention group.

The study showed that treatment of patients even with mild hyperglycaemia benefits not only the mother but the child too: less weight gain during pregnancy may increase the chance of returning to normal body weight after birth, resulting in a lower risk of future metabolic disorders. On the other hand, the literature data suggests that hyperglycaemia in the fetal period significantly influences the risk of metabolic complications for offspring in later life [12-14]. The results of a British study conducted by the National Institute of Health evaluating the cost and effectiveness of health care for patients with GDM indicate that screening, diagnosis and treatment of gestational diabetes is effective [17]. Another randomized study also found that although treating mild hyperglycaemia appears to have beneficial effects on the risk of macrosomia, shoulder dystocia, frequency of caesarean delivery, preeclampsia and hypertension compared to a control group, no differences were observed between the groups regarding the incidence of the composite endpoint of perinatal death, hyperbilirubinaemia, hypoglycaemia, hyperinsulinaemia and perinatal injuries [18]. The efficacy of treating GDM has also been demonstrated in other studies [19].

Available studies on the impact of maternal hyperglycaemia on obstetric outcome are limited by the fact that they involve groups of patients diagnosed with GDM, without any representative control population of healthy women. It should be emphasized that the present study, like the majority of published studies, evaluates the results of women diagnosed with hyperglycaemia, thus obtaining adequate glycaemic data, while referring them to a population of healthy pregnant women. The authors of the HAPO study indicate that one key limitation of the study is that no results were available regarding the nutritional status and gestational weight gain of women, which may account for the differences observed between the HAPO results and our present analysis. In addition, indications for caesarean section may have resulted from factors such as maternal BMI, previous gestational diabetes or previously diagnosed macrosomia. In Polish conditions, maternal preferences during pregnancy also are a major factor, which is why way of terminating the pregnancy seems to be burdened with too big error to be able to conclude on this basis.

It has been estimated that the number of women diagnosed with GDM would rise following the implementation of new WHO guidelines in 2013. In the HAPO study, the mean incidence of GDM was $17.8 \%$ based on the new criteria. To date, no data exists on the actual number of women with GDM in the Polish population. Due to the expected enlargement of the population of women diagnosed with GDM who will require specialist care, it seems reasonable to examine the efficacy and costs in accordance with the new guidelines and the implementation of individualized education and self-control. Time will reveal the health effects and costs of the newly-introduced GDM diagnostic criteria.

\section{REFERENCES}

1. Jensen DM, Damm P, Sørensen B, [et al.]. Clinical impact of mild carbohydrate intolerance in pregnancy: a study of 2904 nondiabetic Danish women with risk factors for gestational diabetes mellitus. Am J Obstet Gynecol. 2001, 185, 413-419.

2. Jensen DM, Korsholm L, Ovesen P, Beck-Nielsen $H$, Mølsted-Pedersen $\mathrm{L}$, Damm P. Adverse pregnancy outcome in women with mild glucose intolerance: is there a clinically meaningful threshold value for glucose? Acta Obstet Gynecol Scand. 2008, 87, 59-62.

3. Definition, Diagnosis and Classification of Diabetes Mellitus and its Complications. Report of a WHO Consultation. Geneva 1999.

4. HAPO Study Cooperative Research Group; Metzger BE, Lowe LP, Dyer AR, Trimble ER, [et al.]. Hyperglycemia and adverse pregnancy outcomes. NEngl J Med. 2008, 358, 1991-2002.

5. IADPSG Consensus Panel. Diabetes Care. 2010, 33, 676-682.

6. Diagnostic Criteria and Classification of Hyperglycemia First Detected in Pregnancy, Report of World Health Organization, 2013.

7. Zalecenia kliniczne dotyczące postępowania u chorych na cukrzycę 2014. Diabetologia Kliniczna. 2014, 3, suppl. A, A1-A71.

8. Malewski A, Słomko Z, Klejewski A. Relacja wieku ciążowego i masy urodzeniowej noworodków z regionu Wielkopolski. Medycyna Wieku Rozwojowego. 2001, 2 (suppl. I).

9. Zawiejska A, Wender-Ożegowska E, Radzicka S, Brązert J. Maternal hyperglycemia according to IADPSG criteria as a predictor of perinatal complications in women with gestational diabetes. A retrospective observational study. J Matern Fetal Neonatal Med. 2014, 27, 1526-1530.

10. Ferrara A, Weiss NS, Hedderson MM, [et al.]. Pregnancy plasma glucose levels exceeding the American Diabetes Association thresholds, but below the National Diabetes Data Group thresholds for gestational diabetes mellitus, are related to the risk of neonatal macrosomia, hypoglycaemia and hyperbilirubinaemia. Diabetologia. 2007, 50, 298-306.

11. Sacks DA, Greenspoon JS, Abu-Fadil S, Henry HM, Wolde-Tsadik G, Yao JF. Toward universal criteria for gestational diabetes: the 75-gram glucose tolerance test in pregnancy. Am J Obstet Gynecol. 1995, 172, 607-614.

12. Silverman BL, Metzger BE, Cho NH, Loeb CA. Impaired glucose tolerance in adolescent offspring of diabetic mothers. Relationship to fetal hyperinsulinism. Diabetes Care. 1995, 18, 611-617.

13. Innes KE, Byers TE, Marshall JA, Barón A, Orleans M, Hamman RF. Association of a woman's own birth weight with subsequent risk for gestational diabetes. JAMA. 2002, 287, 2534-2541. Erratum in: JAMA. 2002, 287, 3212. 
14. Pettitt DJ, Knowler WC. Long-term effects of the intrauterine environment, birth weight, and breast-feeding in Pima Indians. Diabetes Care. 1998, 21 (suppl. 2), B138-B141.

15. Ogonowski J, Miazgowski T, Engel K, Celewicz Z. Birth weight predicts the risk of gestational diabetes mellitus and pregravid obesity. Nutrition. 2014, 30, 39-43.

16. Crowther CA, Hiller JE, Moss JR, McPhee AJ, Jeffries WS, Robinson JS; Australian Carbohydrate Intolerance Study in Pregnant Women (ACHOIS) Trial Group. Effect of treatment of gestational diabetes mellitus on pregnancy outcomes. N Engl J Med. 2005, 352, 247-2486.
17. National Collaborating Centre for Women's and Children's Health Diabetes in Pregnancy: Management of Diabetes and Its Complications from Preconception to the Postnatal Period. London, U.K., RCOG Press, 2008.

18. Landon MB, Spong CY, Thom E, [et al.]; Eunice Kennedy Shriver National Institute of Child Health and Human Development Maternal-Fetal Medicine Units Network. A multicenter, randomized trial of treatment for mild gestational diabetes. N Engl J Med. 2009, 361, 1339-1348.

19. Langer O, Yogev Y, Most O, Xenakis EM. Gestational diabetes: the consequences of not treating. Am J Obstet Gynecol. 2005, 192, 989-997.

24. Opole - SP ZOZ nad Matką i Dzieckiem w Opolu

25. Police - PUM w Szczecinie Szpital Kliniczny Nr 1. Klinika Diabetologii i Chorób Wewnętrznych

26. Police - Szpital Kliniczny Nr 1. Klinika Medycyny Matczyno-Płodowej i Ginekologii

27. Poznań - Ginekologiczno-Położniczy Szpital Kliniczny UM im. K. Marcinkowskiego. Poradnia Diabetologiczna dla ciężarnych

28. Przemyśl - 114 Szpital Wojskowy z Przychodnią SP ZOZ. Poradnia Diabetologiczna i Chorób Metabolicznych

29. Ruda Śląska - NZOZ Przychodnia Specjalistyczna Andrzej Wittek, Henryk Rudzki S.C.

30. Rzeszów - Szpital Wojewódzki nr 2. im. Św. Królowej Jadwigi. Poradnia Diabetologiczna

31. Rzeszów - NZOZ"Diabetologia"

32. Sosnowiec - Przychodnia Rejonowo-Specjalistyczna nr 20. Poradnia Diabetologiczna

33. Suwałki - Szpital Wojewódzki w Suwałkach. Poradnia Diabetologiczna

34. Szczecin - Wojewódzki Szpital Zespolony im. Marii Skłodowskiej-Curie

35. Toruń - Wojewódzki Szpital Zespolony im. L. Rydygiera. Wojewódzkie Centrum Diabetologii

36. Tychy - Szpital Miejski, Poradnia Diabetologiczna

37. Warszawa - CSK UM im. Banacha, Poradnia Diabetologiczna

38. Warszawa - Poliklinika Bródnowskiego Centrum Klinicznego. Poradnia Diabetologiczna

39. Warszawa - Szpital Kliniczny Dzieciątka Jezus. Klinika Położnictwa i Ginekologii

40. Warszawa - Szpital Kliniczny im. Ks. Anny Mazowieckiej

41. Wrocław - Akademicki Szpital Kliniczny im. Jana Mikulicza-Radeckiego

42. Zamość - Szpital Wojewódzki. Poradnia Diabetologiczna

43. Zielona Góra - SP ZOZ im. Karola Marcinkowskiego. Oddział chorób wewnętrznych z pododdziałem diabetologii, gastroenterologii i hematologii

44. Żory - NZOZMED-ART. Poradnie Specjalistyczne sp. zo.o. 